\title{
Agreement on the Level Selection in Laminoplasty among Experienced Surgeons: A Survey-Based Study
}

\author{
Jae Hwan Cho ${ }^{1}$, Kyung-Soo Suk ${ }^{2}$, Jong-Beom Park ${ }^{3}$, Jung-Ki Ha ${ }^{1}$, \\ Chang Ju Hwang ${ }^{1}$, Choon Sung Lee ${ }^{1}$, Dong-Ho Lee ${ }^{1}$ \\ ${ }^{I}$ Department of Orthopedic Surgery, Asan Medical Center, University of Ulsan College of Medicine, Seoul, Korea \\ ${ }^{2}$ Department of Orthopaedic Surgery, Gangnam Severance Hospital, Yonsei University College of Medicine, Seoul, Korea \\ ${ }^{3}$ Department of Orthopedic Surgery, Uijeongbu St. Mary's Hospital, Uijeongbu, Korea
}

Study Design: Survey based study.

Purpose: To assess the degree of agreement in level selection of laminoplasty (LP) for the selected cervical myeloradiculopathy cases between experienced spine surgeons.

Overview of Literature: Although, cervical LP is a widely used surgical technique for multi-level spinal cord compression, until now there is no consensus about how many segments or which segments should be opened to achieve a satisfactory decompression.

Methods: Thorough clinical and radiographic data (plain X-ray, computed tomography, and magnetic resonance imaging) of 30 patients who had cervical myelopathy were prepared. The data were provided to three independent spine surgeons with over 10 years experience in operation of their own practices. They were questioned about the most preferable surgical method and suitable decompression levels. The second survey was carried out after 6 months with the same cases. If the level difference between respondents was a half level or below, agreement was considered acceptable. The intraobserver and interobserver agreements in level selection were assessed by kappa statistics.

Results: Three respondents selected LP as an option for 6, 8, and 22 cases in the first survey and 10, 21, and 24 cases in the second survey. The reasons for selection of LP were levels of ossification of the posterior longitudinal ligament $(p=0.004)$, segmental kyphotic deformity $(p=0.036)$ and mean compression score $(p=0.041)$. Intraobserver agreement showed variable results. Interobserver agreement was poor to fair by perfect matching (kappa=0.111-0.304) and fair to moderate by acceptable matching (kappa=0.308-0.625) . Conclusions: The degree of agreement for level selection of LP was not high even though experienced surgeons would choose the opening segments on the basis of same criteria. These results suggest that more specific guidelines in determination of levels for LP should be required to decrease unnecessary wide decompression according to individual variance.

Keywords: Cervical vertebrae; Spinal cord comression; Laminoplasty; Surveys and questionnaires

\section{Introduction}

Several factors affect surgical decisions regarding approaches and levels in cervical myeloradiculopathy caused by spondylosis or ossification of the posterior longitudinal ligament (OPLL) [1]. In general, sagittal alignment, involved levels, symptoms, bone quality, and surgical preference are all considered when selecting appropriate

\footnotetext{
Received Nov 27, 2015; Accepted Dec 12, 2015

Corresponding author: Dong-Ho Lee

Department of Orthopedic Surgery, Asan Medical Center, University of Ulsan College of Medicine,

88 Olympic-ro 43-gil, Songpa-gu, Seoul 05505, Korea

Tel: +82-2-3010-3898, Fax: +82-2-3010-8555, E-mail: osdlee@gmail.com
} 
surgical options. However, even selection between the anterior and posterior approaches is not as easy as might be imagined $[2,3]$. The value of randomization of surgical approaches in cervical spondylotic myelopathy cases has been analyzed [4]. In that study, it was reported that more than 5 degrees of cervical kyphosis or a segmental cervical kyphotic deformity typically led to a surgeon recommended anterior approach. Other than such cases, however, the best approach remains contentious.

Laminoplasty (LP) is considered valid when the best course of action is uncertain. The conventional indication of LP has been cervical myelopathy in cases with multilevel involvement without kyphotic deformity. However, the definite criteria are uncertain because so many factors are related to the decision process. In addition, level selection in LP is another complex decision that requires considerable experience. Although the level of conventional $\mathrm{LP}$ ranges from $\mathrm{C} 3$ to $\mathrm{C} 7$, level selection has been variable when using emerging selective LP or dome LP $[5,6]$. However, there is no consensus about how many segments or which segments should be opened to achieve a satisfactory decompression. The purpose of this study was to address the variability in level selection of LP and also to screen for related factors in the selection of LP for cervical myeloradiculopathy cases by conducting surveys of experienced cervical spine surgeons.

\section{Materials and Methods}

\section{Survey design}

This study was a survey-based descriptive analysis that was approved by the Institutional Review Board of our hospital. Thirty cervical myeloradiculopathy patients including cases of spondylosis and OPLL that required surgery were recruited from the same institute for the survey which included basic demographic data, descriptions of symptoms, physical examinations, and radiographic data. The cases showing more than 10 degrees of cervical kyphosis or considerable neck pain (visual analog scale $\geq 3$ ) were excluded in this survey. Plain radiographs contained cervical spine anteroposterior, lateral views, and dynamic lateral views. Sagittal and axial images of each level from $\mathrm{C} 2$ to $\mathrm{T} 1$ were captured using computed tomography (CT) and magnetic resonance imaging (MRI). The first survey included questions about (1) the most preferable surgical method and (2) the suitable decompression levels. The baseline characteristics of 30 survey cases are described in Table 1. C2-C7 lordosis was defined as an angle between the upper endplate of $\mathrm{C} 2$ and $\mathrm{C} 7$, and was measured using Cobb's method in lateral neutral radiographs. Segmental kyphotic deformity was defined as positive if three or more levels of disc-osteophyte extended dorsally to a line drawn between the dorsal caudal point of $\mathrm{C} 2$ and that of C7 in sagittal reconstructed CT images [4]. The degree of cord compression was defined using a grading system, with a T2-weighted sagittal section of MRI data obtained as previously described [7]. Each grade was denoted as: grade 0 , normal; grade 1 , more than $50 \%$ subarachnoid obliteration without any cord deformity; grade 2, definite cord deformity without signal change and grade 3 , definite cord deformity with increased signal intensity in T2-weighted images. The mean compression score was defined as the sum of compression grades in each level divided by the number of compressions. The extents of compression, OPLL and foraminal stenosis were counted by determining the involved levels from $\mathrm{C} 2$ to $\mathrm{T} 1$. A representative case is illustrated in Fig. 1.

The concept of "acceptable agreement" was introduced to assess the degree of agreement in the level selection for LP [8]. If the difference was a half level or less, the degree of agreement was considered acceptable. An example for the acceptable agreement is described in Fig. 2. The dome LP was considered as a half level. Three experienced spine surgeons who had their own practice for more than 10 years conducted the first survey. Given that all of the surgeons worked at other institutes, the participants were blind to the objectives of the survey. The second survey was conducted 6 months after the initial survey but its focus was slightly different to the first survey. The surgeons were queried on the acceptability for LP as a treatment option and suitable decompression levels.

\section{Statistical analyses}

The approaches and levels of response were analyzed descriptively. The intraobserver and interobserver agreements in level selection for LP were assessed by kappa statistics. The kappa values were evaluated as follows: poor, $<0.20$; fair, between 0.21 and 0.40 ; moderate, between 0.41 and 0.60 ; good, between 0.61 and 0.80 ; and excellent, $>0.80$. The factors that were related to decisions to perform LP in each respondent were revealed by Student's $t$-test, chi-square test, Mann-Whitney $U$-test, or Fisher's 
Table 1. Baseline characteristics of 30 survey cases

\begin{tabular}{|c|c|c|c|c|c|c|c|c|c|c|}
\hline$N$ & Sex & $\begin{array}{l}\text { Age } \\
\text { (yr) }\end{array}$ & $\begin{array}{l}\text { Sx onset } \\
\text { (mo) }\end{array}$ & $\begin{array}{c}\text { Motor } \\
\text { weakness }\end{array}$ & $\begin{array}{l}\text { C2-C7 } \\
\text { lordosis }^{\text {a) }}\end{array}$ & SKD & $\begin{array}{l}\text { Levels of } \\
\text { compression }\end{array}$ & MCS & $\begin{array}{l}\text { Levels of } \\
\text { OPLL }\end{array}$ & $\begin{array}{r}\text { Foramina } \\
\text { stenosis }\end{array}$ \\
\hline 1 & Female & 54 & 9 & Y & 11.3 & Y & 3 & 2.00 & 0 & 2 \\
\hline 2 & Male & 60 & 2 & $Y$ & 15.9 & $\mathrm{~N}$ & 5 & 1.80 & 5 & 0 \\
\hline 3 & Female & 72 & 120 & $Y$ & 0.6 & $Y$ & 4 & 1.50 & 0 & 4 \\
\hline 4 & Male & 68 & 14 & $\mathrm{~N}$ & 1.4 & $\mathrm{~N}$ & 5 & 1.80 & 5 & 1 \\
\hline 5 & Female & 67 & 20 & $\mathrm{~N}$ & -3.6 & $Y$ & 4 & 1.25 & 3 & 3 \\
\hline 6 & Female & 72 & 7 & $Y$ & 29.2 & $\mathrm{~N}$ & 3 & 1.67 & 2 & 0 \\
\hline 7 & Male & 55 & 6 & $\mathrm{~N}$ & 9.4 & $\mathrm{~N}$ & 5 & 1.80 & 5 & 0 \\
\hline 8 & Female & 62 & 2 & $Y$ & 12.0 & $\mathrm{~N}$ & 4 & 1.50 & 4 & 0 \\
\hline 9 & Female & 48 & 8 & $Y$ & -1.0 & $Y$ & 3 & 1.67 & 1 & 2 \\
\hline 10 & Female & 69 & 6 & $\mathrm{~N}$ & -7.6 & $Y$ & 4 & 2.25 & 0 & 1 \\
\hline 11 & Male & 63 & 3 & Y & 23.7 & $\mathrm{~N}$ & 2 & 2.00 & 0 & 2 \\
\hline 12 & Male & 56 & 3 & Y & -4.9 & $Y$ & 4 & 1.25 & 0 & 0 \\
\hline 13 & Female & 55 & 6 & Y & -4.7 & $Y$ & 2 & 1.50 & 0 & 1 \\
\hline 14 & Female & 78 & 5 & $Y$ & -7.9 & $\mathrm{~N}$ & 5 & 1.20 & 0 & 2 \\
\hline 15 & Female & 65 & 1 & $\mathrm{~N}$ & 0.6 & $\mathrm{~N}$ & 5 & 1.80 & 0 & 2 \\
\hline 16 & Male & 33 & 3 & $\mathrm{~N}$ & 11.3 & $\mathrm{~N}$ & 3 & 2.00 & 0 & 1 \\
\hline 17 & Male & 59 & 3 & $Y$ & 3.9 & $\mathrm{~N}$ & 5 & 1.60 & 0 & 2 \\
\hline 18 & Male & 56 & 3 & $Y$ & -0.9 & $\mathrm{~N}$ & 4 & 2.00 & 0 & 3 \\
\hline 19 & Male & 67 & 7 & $Y$ & 17.3 & $\mathrm{~N}$ & 4 & 2.50 & 1 & 2 \\
\hline 20 & Male & 58 & 3 & $\mathrm{~N}$ & 19.6 & $\mathrm{~N}$ & 5 & 1.80 & 5 & 1 \\
\hline 21 & Male & 47 & 1 & $Y$ & 17.9 & $\mathrm{~N}$ & 4 & 1.75 & 0 & 2 \\
\hline 22 & Male & 55 & 18 & $Y$ & 19.9 & $\mathrm{~N}$ & 4 & 2.25 & 0 & 2 \\
\hline 23 & Female & 78 & 3 & Y & -2.9 & $Y$ & 5 & 1.60 & 2 & 0 \\
\hline 24 & Male & 63 & 3 & $\mathrm{~N}$ & 18.4 & $\mathrm{~N}$ & 4 & 1.75 & 0 & 3 \\
\hline 25 & Female & 56 & 1 & $\mathrm{~N}$ & -0.4 & $Y$ & 5 & 2.00 & 2 & 2 \\
\hline 26 & Male & 54 & 3 & $Y$ & -3.3 & $Y$ & 3 & 2.00 & 3 & 2 \\
\hline 27 & Male & 48 & 1 & $Y$ & 1.6 & $Y$ & 4 & 2.50 & 3 & 4 \\
\hline 28 & Male & 60 & 5 & $\mathrm{~N}$ & 1.6 & $Y$ & 5 & 1.60 & 2 & 1 \\
\hline 29 & Male & 57 & 3 & $\mathrm{~N}$ & 7.7 & $Y$ & 5 & 1.80 & 0 & 4 \\
\hline 30 & Male & 61 & 3 & $\mathrm{~N}$ & -2.8 & $Y$ & 4 & 1.75 & 0 & 1 \\
\hline
\end{tabular}

N, case number; Sx, symptom; Y, yes; N, no; SKD, segmental kyphotic deformity; MCS, mean compression score; OPLL, ossification of posterior longitudinal ligament.

${ }^{\text {al }}$ Negative means kyphosis.

exact test. The related factors derived by univariate analysis were also assessed by multivariate logistic regression analysis using a stepwise backward manner. Statistical analyses were performed using the SPSS ver. 21.0 (SPSS Inc, Chicago, IL, USA). A $p$-value $<0.05$ was considered statistically significant.

\section{Results}

\section{Selection of LP and related factors}

The numbers of selected LP procedures reported in the first survey by the three surgeons were 6,8 , and 22 . These values increased to 10,21 , and 24 in the same respective 

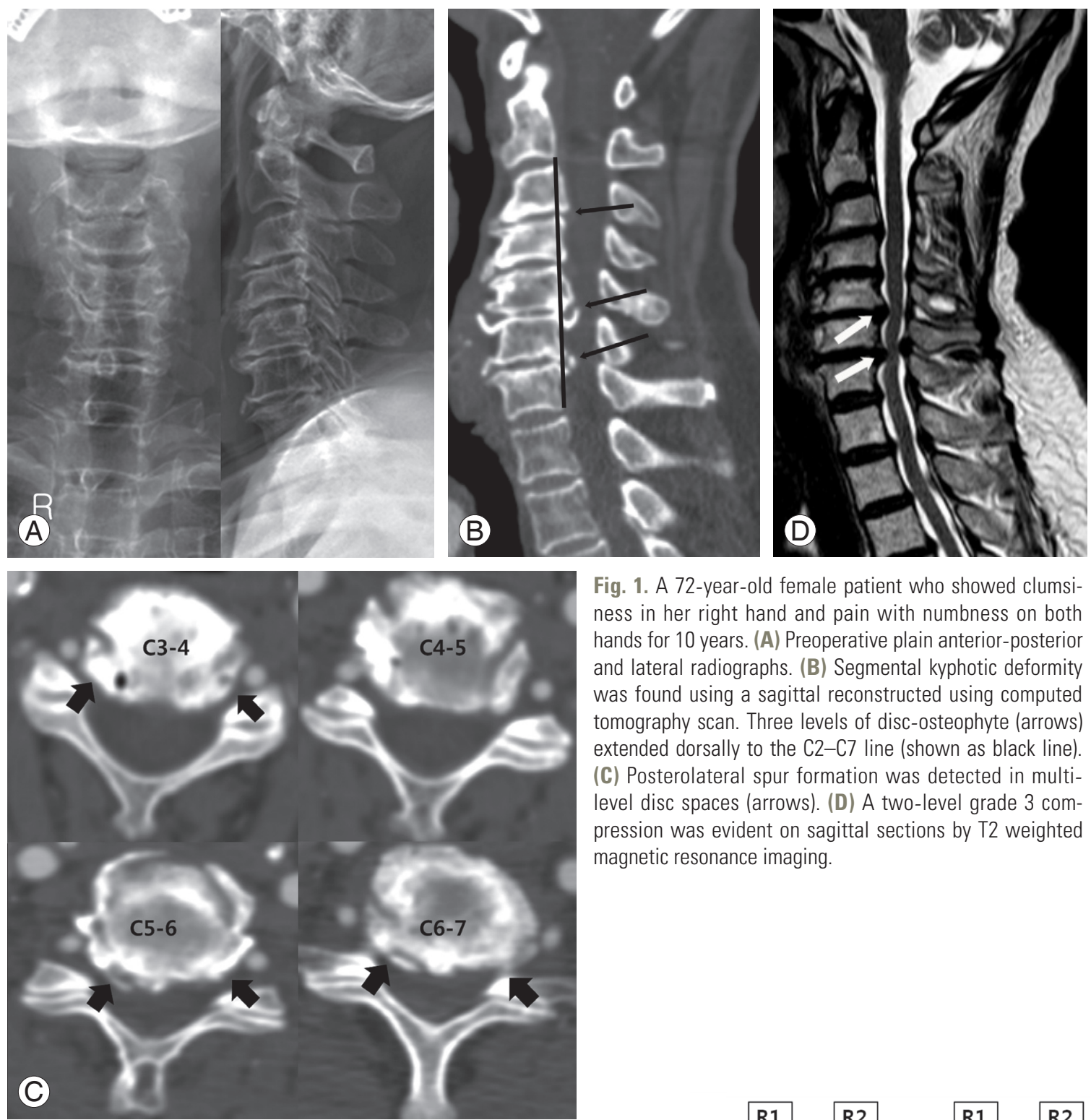

order in the second survey. The details regarding the choice of LP for each case are described in Table 2. The related factors involved in selecting LP were assessed. The number of compression by OPLL and number of foraminal spurs (stenosis) were significant in univariate analysis, and the number of compression by OPLL was the only significantly related factor in multivariate analysis by the first respondent ( $p=0.004)$. In a similar manner, segmental kyphotic deformity listed by the second respondent $(p=0.036)$ and the mean compression score by the third respondent $(p=0.041)$ were related factors that were confirmed by multivariate analysis. Factors related to the selection of LP are summarized in Table 3.
Fig. 1. A 72-year-old female patient who showed clumsiness in her right hand and pain with numbness on both hands for 10 years. (A) Preoperative plain anterior-posterior and lateral radiographs. (B) Segmental kyphotic deformity was found using a sagittal reconstructed using computed tomography scan. Three levels of disc-osteophyte (arrows) extended dorsally to the C2-C7 line (shown as black line). (C) Posterolateral spur formation was detected in multilevel disc spaces (arrows). (D) A two-level grade 3 compression was evident on sagittal sections by $\mathrm{T} 2$ weighted magnetic resonance imaging.

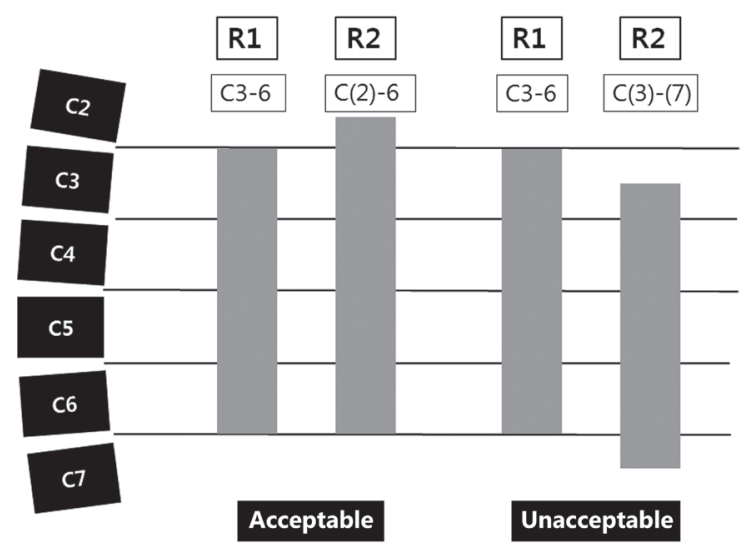

Fig. 2. The concept of acceptable agreement in terms of level selection. In the case on the left, the disparity between R1 and R2 is a half level, which is "acceptable agreement" (bracket means dome laminoplasty and is considered half level). In the case on the right, the disparity is one level, which is "unacceptable agreement". R1, the first respondent; R2, the second respondent. 
Table 2. Choices of laminoplasty and levels determined by each respondent

\begin{tabular}{|c|c|c|c|c|c|c|c|c|c|c|c|c|}
\hline \multirow{3}{*}{$\begin{array}{l}\text { Case } \\
\text { No. }\end{array}$} & \multicolumn{6}{|c|}{ Choice of LP } & \multicolumn{6}{|c|}{ Levels $^{\mathrm{a})}$} \\
\hline & \multicolumn{3}{|c|}{ 1st } & \multicolumn{3}{|c|}{ 2nd } & \multicolumn{3}{|c|}{$1 \mathrm{st}$} & \multicolumn{3}{|c|}{ 2nd } \\
\hline & $\mathrm{R} 1$ & $\mathrm{R} 2$ & R3 & $\mathrm{R} 1$ & $\mathrm{R} 2$ & R3 & $\mathrm{R} 1$ & $\mathrm{R} 2$ & R3 & $\mathrm{R} 1$ & $\mathrm{R} 2$ & R3 \\
\hline 1 & $\mathrm{~N}$ & $\mathrm{~N}$ & N & N & Y & Y & & & & & C4-(7) & C4-(7) \\
\hline 2 & Y & Y & Y & Y & Y & Y & C3-(7) & $C(2)-(7)$ & C3-(7) & C3-(6) & $C(2)-(7)$ & $C(2)-(6)$ \\
\hline 3 & $\mathrm{~N}$ & N & N & N & N & N & & & & & & \\
\hline 4 & Y & Y & Y & Y & Y & Y & $C(2)-(7)$ & $C(2)-(7)$ & $C(2)-6$ & $C(2)-(7)$ & $C(2)-(7)$ & $C(2)-(7)$ \\
\hline 5 & $\mathrm{~N}$ & $\mathrm{~N}$ & N & N & N & Y & & & & & & $\mathrm{C}(3)-\mathrm{T} 1$ \\
\hline 6 & Y & Y & Y & Y & Y & Y & C3-6 & $C(2)-(6)$ & $C(2)-(5)$ & $C(2)-5$ & C3-(6) & $C(2)-4$ \\
\hline 7 & Y & Y & Y & Y & Y & Y & C3-5 & $C(2)-(7)$ & $C(2)-(5)$ & $C(2)-(6)$ & $C(2)-(7)$ & C3-4 \\
\hline 8 & Y & Y & Y & Y & Y & Y & C3-(6) & С3-6 & C3-5 & C3-5 & C3-(7) & C3-(6) \\
\hline 9 & $\mathrm{~N}$ & $\mathrm{~N}$ & N & N & N & N & & & & & & \\
\hline 10 & $\mathrm{~N}$ & N & Y & N & N & Y & & & C4-(7) & & & C4-(7) \\
\hline 11 & $\mathrm{~N}$ & N & N & N & N & N & & & & & & \\
\hline 12 & $\mathrm{~N}$ & N & Y & N & Y & N & & & $C 4-(7)$ & & $C(4)-(7)$ & \\
\hline 13 & $\mathrm{~N}$ & $\mathrm{~N}$ & N & N & N & N & & & & & & \\
\hline 14 & N & N & N & N & Y & N & & & & & $C(2)-(7)$ & \\
\hline 15 & $\mathrm{~N}$ & N & Y & N & Y & Y & & & $C(3)-(7)$ & & $C(3)-(7)$ & $C(3)-(7)$ \\
\hline 16 & $\mathrm{~N}$ & N & Y & N & Y & Y & & & $C(3)-(7)$ & & C3-(7) & C3-(7) \\
\hline 17 & $\mathrm{~N}$ & $\mathrm{~N}$ & Y & Y & Y & Y & & & $C(2)-4$ & C3-6 & $C(2)-(7)$ & $C(2)-4$ \\
\hline 18 & $\mathrm{~N}$ & N & Y & N & Y & Y & & & C4-(7) & & C3-(7) & C4-(7) \\
\hline 19 & $\mathrm{~N}$ & $\mathrm{~N}$ & Y & $\mathrm{N}$ & N & Y & & & C3-(7) & & & C3-(6) \\
\hline 20 & $\mathrm{~N}$ & Y & Y & Y & Y & Y & & $C(2)-(7)$ & C3-(6) & С3-6 & C3-(7) & C3-6 \\
\hline 21 & $\mathrm{~N}$ & Y & Y & Y & Y & Y & & $C(3)-(7)$ & $C(3)-(7)$ & C4-7 & $C(3)-(7)$ & $C(3)-(7)$ \\
\hline 22 & $\mathrm{~N}$ & N & Y & N & Y & Y & & & C3-(7) & & C3-(7) & C3-(7) \\
\hline 23 & $\mathrm{~N}$ & N & Y & Y & N & Y & & & $C(2)-(7)$ & $C(2)-6$ & & $C(2)-6$ \\
\hline 24 & $\mathrm{~N}$ & N & Y & N & Y & Y & & & C4-(7) & & C4-(7) & $C(3)-(7)$ \\
\hline 25 & $\mathrm{~N}$ & N & N & $\mathrm{N}$ & Y & Y & & & & & $C(3)-(7)$ & C3-6 \\
\hline 26 & $Y$ & Y & Y & Y & Y & Y & $C(2)-7$ & $C(2)-(6)$ & $C(2)-4$ & $C(2)-5$ & $C(2)-5$ & $C(2)-4$ \\
\hline 27 & $\mathrm{~N}$ & $\mathrm{~N}$ & Y & N & Y & Y & & & C3-(6) & & C3-(7) & C3-6 \\
\hline 28 & $\mathrm{~N}$ & $N$ & Y & N & Y & Y & & & $C(2)-6$ & & $C(2)-(7)$ & $C(2)-6$ \\
\hline 29 & $\mathrm{~N}$ & $\mathrm{~N}$ & Y & $\mathrm{N}$ & Y & Y & & & $C(2)-(7)$ & & C3-(7) & $C(2)-(7)$ \\
\hline 30 & $\mathrm{~N}$ & $\mathrm{~N}$ & Y & $\mathrm{N}$ & N & Y & & & C3-(7) & & & C3-(7) \\
\hline
\end{tabular}

LP, laminoplasty; R1, the first respondent; R2, the second respondent; R3, the third respondent; $Y$, yes; $N$, no.

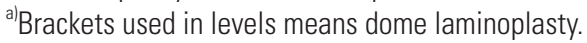

\section{Intraobserver and interobserver agreement in the se- lection of LP}

The suggested level selections for LP from each respondent are indicated in Table 2. The intraobserver agreement was poor to moderate with perfect matching $(0.143,0.467$, and 0.464) and variable with acceptable matching (0.294, 1.000 , and 0.851$)$. The interobserver agreement in the first survey was poor with perfect matching $(0.143,0.143$, and 0.111$)$ and variable with acceptable matching $(0.625$, 0.455 , and 0.344$)$. The interobserver agreement in the second survey was fair $(0.203,0.278$, and 0.304$)$ with perfect 
Table 3. Related factors for selecting laminoplasty in the second survey

\begin{tabular}{|c|c|c|c|}
\hline Factors & Mean value (LP vs. non-LP) & Univariate & Multivariate \\
\hline \multicolumn{4}{|l|}{ R1 } \\
\hline Levels of OPLL & 3.10 vs. 0.60 & $p=0.003$ & $p=0.004$ \\
\hline Levels of foraminal stenosis & 0.80 vs. 2.10 & $p=0.004$ & \\
\hline SKD & $0.2(2 / 10)$ vs. $0.6(12 / 20)$ & $p=0.058$ & \\
\hline \multicolumn{4}{|l|}{ R2 } \\
\hline Levels of compression & 4.29 vs. 3.56 & $p=0.041$ & \\
\hline SKD & 0.33 (7/21) vs. 0.78 (7/9) & $p=0.046$ & $p=0.036$ \\
\hline Kyphosis & 0.24 (5/21) vs. 0.67 (6/9) & $p=0.042$ & \\
\hline \multicolumn{4}{|l|}{ R3 } \\
\hline Mean compression score & 1.86 vs. 1.52 & $p=0.016$ & $p=0.041$ \\
\hline Levels of OPLL & 1.75 vs. 0.17 & $p=0.001$ & \\
\hline
\end{tabular}

LP, laminoplasty; R1, the first respondent; OPLL, ossification of posterior longitudinal ligament; SKD, segmental kyphotic deformity; R2, the second respondent; $\mathrm{R} 3$, the third respondent.

Table 4. Intraobserver and interobserver agreements in level selections of laminoplasty

\begin{tabular}{|c|c|c|c|c|c|c|}
\hline & $\begin{array}{l}\text { Choice of LP } \\
\text { in common }\end{array}$ & $\begin{array}{c}\text { Perfect } \\
\text { agreement } \\
\text { (n }[\%])\end{array}$ & $\begin{array}{l}\text { Kappa } \\
\text { value }\end{array}$ & $\begin{array}{c}\text { Average } \\
\text { disagreement }\end{array}$ & $\begin{array}{c}\text { Acceptable } \\
\text { agreement }^{\text {a) }} \\
\text { (n }[\%])\end{array}$ & Kappa value \\
\hline R1-1 vs. R1-2 & 6 & $1(16.6)$ & 0.143 & $1.00(6 / 6)$ & $2(33.3)$ & 0.294 \\
\hline R2-1 vs. R2-2 & 8 & $4(50.0)$ & 0.467 & $0.25(4 / 8)$ & 8 (100.0) & 1.000 \\
\hline R3-1 vs. R3-2 & 21 & $10(47.6)$ & 0.464 & $0.36(7.5 / 21)$ & 18 (85.7) & 0.851 \\
\hline R1-1 vs. R2-1 & 6 & 1 (16.6) & 0.143 & $0.83(5 / 6)$ & 4 (66.6) & 0.625 \\
\hline R1-1 vs. R3-1 & 6 & $1(16.6)$ & 0.143 & $1.00(6 / 6)$ & $3(50.0)$ & 0.455 \\
\hline R2-1 vs. R3-1 & 8 & $1(12.5)$ & 0.111 & $1.00(8 / 8)$ & $3(37.5)$ & 0.344 \\
\hline R1-2 vs. R2-2 & 9 & $2(22.2)$ & 0.203 & $0.83(7.5 / 9)$ & $3(33.3)$ & 0.308 \\
\hline R1-2 vs. R3-2 & 10 & $3(30.0)$ & 0.278 & $0.85(8.5 / 10)$ & $5(50.0)$ & 0.474 \\
\hline R2-2 vs. R3-2 & 19 & $6(31.6)$ & 0.304 & $0.79(15 / 19)$ & 11 (57.9) & 0.566 \\
\hline
\end{tabular}

Rx-y means ' $x$ ' respondent and ' $y$ ' survey.

$\mathrm{LP}$, laminoplasty.

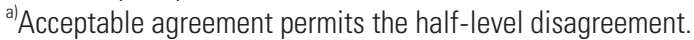

matching and fair to moderate with acceptable matching $(0.308,0.474$, and 0.566$)$. The average disagreement levels between respondents ranged from 0.79 to 1.00 . The overall results of agreement are summarized in Table 4 .

\section{Discussion}

Cervical spondylotic myelopathy or OPLL is a common condition that provokes cervical cord compression and requires surgical decompression. However, debate persists about selecting anterior or posterior approaches [4,9-11].
Many studies have shown good clinical and radiological outcomes with anterior, posterior or combined approaches. Notwithstanding the general agreement about the most appropriate approach, such as posterior approach for multi-level involvement and anterior approach for kyphotic deformity, definite guidelines have not been established $[9,11]$. In some cases, radiological patterns have been used to select a surgical approach for cervical spondylotic myelopathy, although definite conclusions have never been reached [12]. Likewise, there is currently no definite consensus about the selection of either wide-level 
surgery or minimal-level surgery. In particular, LP could have a wide range of options in terms of level selection. Although conventional LP involves the opening of laminae from the third to seventh cervical vertebrae, newly developed concepts such as selective LP or dome LP have rendered level selection more complex [13-15].

Our current study has a few notable findings. Our first respondent did not prefer LP over other options. Only 6 cases were selected in the first survey and the selected numbers were no higher in the second survey. In contrast, the third respondent showed a considerable preference for LP with over 20 cases selected for this treatment in each survey. Whereas the first survey failed to indicate a preference of the second respondent for LP, the second survey revealed a high level of acceptance of LP as an option. Thus, even experienced surgeons display variability in terms of preference as well as acceptance of LP. This variability might have complicated our results for selection of LP. In addition, we confirmed that dome LP and selective LP was widely used (Table 2). The frequency of selection for dome LP was about 88.9\% (32/36) and 85.5\% (47/55) in each survey. Furthermore, selective LP was considered more frequently than conventional LP, which was not selected at all throughout our surveys. The preference for selective LP might have led to variable level selection, which is one of the reasons for the poor level of agreement between each respondent.

Also of interest were the related factors used to select LP from the results of our second survey. Given that questions in the first survey did not target LP, we analyzed the factors related to the results of our second survey. With the multivariate regression model, only one factor in each respondent was selected as a related factor. The extent of OPLLs reported by the first respondent and the mean compression score reported by the third respondent were related to the level and severity of compression, respectively. LP was chosen if more levels were involved and the degree of compression was more severe. Segmental kyphotic deformity recorded by the second respondent is the factor that was related to cervical sagittal alignment. The factors identified in our surveys are not significantly different from previously suggested indicators for LP, which included multi-level involvement and the absence of kyphosis.

The level of agreement on level selection between the experienced surgeons we surveyed was a primary concern in our current study. Interestingly, the interobserver agree- ment we observed in terms of level selection of LP was relatively lower than expected. The reason for this disparity is thought to be the absence of a universal standard for this level selection. Minimally invasive procedures, such as dome LP, have been introduced previously to minimize disruption of muscle detachment and alleviate axial neck pain and showed favorable outcomes $[5,13]$. The choice of dome LP and selective LP could introduce difficulty in reaching a consensus about the level selections of LP.

There were some limitations to our current study. First, as we used only three respondents, the findings in our present study cannot be generalized. Our focus was to search for the factors that affected the tendency of experienced cervical spine surgeons towards LP and level selections. In addition, the lack of certain data from our surveys was a weakness. For example, dynamic MRI was not included in our survey and is considered to be an important factor that influences decision making by some surgeons $[16,17]$. Furthermore, given that we conducted a survey-based study, clinical correlations were not used. However, the number of cases we examined was thought to be enough for analysis. In addition, the interval between the first and second survey was 6 months, which is sufficient to minimize recall bias, considering that one month is commonly considered an acceptable interval in this regard. These aspects could be regarded as strengths of the current study.

\section{Conclusions}

In summary, the degree of agreement we observed for level selections of LP were not especially high, although the factors related to this decision were not different from previously suggested criteria, i.e. long-level compression and the maintenance of lordosis. We conclude that more specific guidelines for selecting LP appear to be required to decrease unnecessary wide decompression according to individual variance.

\section{Conflict of Interest}

No potential conflict of interest relevant to this article was reported.

\section{References}

1. Lawrence BD, Shamji MF, Traynelis VC, et al. Surgi- 
cal management of degenerative cervical myelopathy: a consensus statement. Spine (Phila Pa 1976) 2013; 38(22 Suppl 1):S171-2.

2. Seng C, Tow BP, Siddiqui MA, et al. Surgically treated cervical myelopathy: a functional outcome comparison study between multilevel anterior cervical decompression fusion with instrumentation and posterior laminoplasty. Spine J 2013;13:723-31.

3. Mummaneni PV, Kaiser MG, Matz PG, et al. Cervical surgical techniques for the treatment of cervical spondylotic myelopathy. J Neurosurg Spine 2009;11: 130-41.

4. Ghogawala Z, Coumans JV, Benzel EC, Stabile LM, Barker FG 2nd. Ventral versus dorsal decompression for cervical spondylotic myelopathy: surgeons' assessment of eligibility for randomization in a proposed randomized controlled trial: results of a survey of the Cervical Spine Research Society. Spine (Phila Pa 1976) 2007;32:429-36.

5. Hosono N, Sakaura H, Mukai Y, Fujii R, Yoshikawa H. C3-6 laminoplasty takes over C3-7 laminoplasty with significantly lower incidence of axial neck pain. Eur Spine J 2006;15:1375-9.

6. Tsuji T, Asazuma T, Masuoka K, et al. Retrospective cohort study between selective and standard C3-7 laminoplasty: minimum 2-year follow-up study. Eur Spine J 2007;16:2072-7.

7. Kang Y, Lee JW, Koh YH, et al. New MRI grading system for the cervical canal stenosis. AJR Am J Roentgenol 2011;197:W134-40.

8. Qvistgaard E, Rasmussen J, Laetgaard J, HecksherSorensen S, Bliddal H. Intra-observer and interobserver agreement of the manual examination of the lumbar spine in chronic low-back pain. Eur Spine J 2007;16:277-82.

9. Fehlings MG, Barry S, Kopjar B, et al. Anterior versus posterior surgical approaches to treat cervical spondylotic myelopathy: outcomes of the prospective multicenter AOSpine North America CSM Study in 264 patients. Spine 2013;38:2247-52.

10. Irwin $\mathrm{ZN}$, Hilibrand A, Gustavel M, et al. Variation in surgical decision making for degenerative spinal disorders. Part II: cervical spine. Spine (Phila $\mathrm{Pa}$ 1976) 2005;30:2214-9.

11. Lin D, Zhai W, Lian K, Kang L, Ding Z. Anterior versus posterior approach for four-level cervical spondylotic myelopathy. Orthopedics 2013;36:e1431-6.

12. Bapat MR, Chaudhary K, Sharma A, Laheri V. Surgical approach to cervical spondylotic myelopathy on the basis of radiological patterns of compression: prospective analysis of 129 cases. Eur Spine J 2008;17: 1651-63.

13. Kato M, Nakamura H, Konishi S, et al. Effect of preserving paraspinal muscles on postoperative axial pain in the selective cervical laminoplasty. Spine (Phila Pa 1976) 2008;33:E455-9.

14. Zhang P, Shen Y, Zhang YZ, Ding WY, Xu JX, Cao JM. Preserving the C7 spinous process in laminectomy combined with lateral mass screw to prevent axial symptom. J Orthop Sci 2011;16:492-7.

15. Iwasaki M, Okuda S, Miyauchi A, et al. Surgical strategy for cervical myelopathy due to ossification of the posterior longitudinal ligament: Part 2: Advantages of anterior decompression and fusion over laminoplasty. Spine (Phila Pa 1976) 2007;32:654-60.

16. Miura J, Doita M, Miyata K, et al. Dynamic evaluation of the spinal cord in patients with cervical spondylotic myelopathy using a kinematic magnetic resonance imaging technique. J Spinal Disord Tech 2009;22:8-13.

17. Zhang L, Zeitoun D, Rangel A, Lazennec JY, Catonne Y, Pascal-Moussellard H. Preoperative evaluation of the cervical spondylotic myelopathy with flexionextension magnetic resonance imaging: about a prospective study of fifty patients. Spine (Phila Pa 1976) 2011;36:E1134-9. 